ARTICLE

\title{
Radiation Transport Calculation Using PHITS Code for the Activation of BigRIPS Separator at RIKEN Radioactive Isotope Beam Factory and Comparison with the Measurement
}

\author{
Kanenobu TANAKA, Naohito INABE, Tetsuya OHNISHI and Toshiyuki KUBO \\ RIKEN Nishina Center, 2-1 Hirosawa, Wako-city, Saitama-ken, 351-0198, Japan
}

\begin{abstract}
At the BigRIPS separator in a heavy-ion accelerator facility RIBF, activation of several metal samples irradiated by secondary particles induced by a ${ }^{48} \mathrm{Ca}$-ion beam was studied. Residual gamma rays were measured by using a Ge detector to deduce the amount of radioactive nuclei. The measurements were compared with calculations of the PHITS transport code.
\end{abstract}

KEYWORDS: heavy ion beams, ${ }^{48} \mathrm{Ca}$ beam, residual activity measurement, in-flight radioactive isotope (RI) beam facility, radiation transport calculation, PHITS code

\section{Introduction}

At a new-generation accelerator facility of Radioactive Isotope Beam Factory (RIBF), a superconducting ring-cyclotron accelerator provides a variety of high-intensity heavy-ion beams up to ${ }^{238} \mathrm{U}$ at around $350 \mathrm{MeV} /$ nucleon. ${ }^{1)}$ The goal of the beam intensity is 1 particle $\mu \mathrm{A}\left(6.2 \times 10^{12}\right.$ particles/s). These heavy-ion beams are converted into intense beams of radioactive isotope via projectile fragmentation of stable isotopes or in-flight fission of uranium isotopes by a BigRIPS superconducting separator ${ }^{2)}$ to study unstable nuclei far from stability.

A heavy-ion beam bombards on a target of the BigRIPS separator and then most of the beam injects into a beam dump and the beam stops in it. Since a beam induces nuclear reactions, a high-intense beam generates a lot of radioactivity especially at the target and the beam dump. For upgrade and maintenance of the BigRIPS, works in radiation environment are necessary. To predict future radiation levels and make plans for these works, we made radiation samples to compare these radioactivities with a Particle and Heavy-Ion Transport code System (PHITS) ${ }^{3)}$ calculation. Until 2009, a high-intense beam provided to the BigRIPS is a ${ }^{48} \mathrm{Ca}$ ion up to 200 particle $\mathrm{nA}$. Currently, radioactivity around the $\mathrm{Bi}$ gRIPS is mainly induced by the ${ }^{48} \mathrm{Ca}$ beam. This is a first benchmark study of a ${ }^{48} \mathrm{Ca}$ beam with the PHITS.

\section{Experiment}

\section{Beam irradiation}

This irradiation experiment was performed at RIBF. Figure 1 shows the experimental setup. Radiation sample sheets were placed in the forward direction of the beam dump of the BigRIPS. A $345 \mathrm{MeV} /$ nucleon ${ }^{48} \mathrm{Ca}$ beam was injected to the beam dump made of copper. These samples were irra-

*Corresponding author, E-mail:ktanaka@riken.jp

(C) 2011 Atomic Energy Society of Japan, All Rights Reserved. diated and activated by the secondary particles from the beam dump. These secondary particles incident into the samples were mainly neutron because most of charged particles were stopped in the beam dump. Sample materials were copper, iron, aluminum, stainless steel (SUS), which are used at the BigRIPS setup. Ingredients of SUS, nickel and chrome, were also measured. Table 1 shows sizes of the samples.

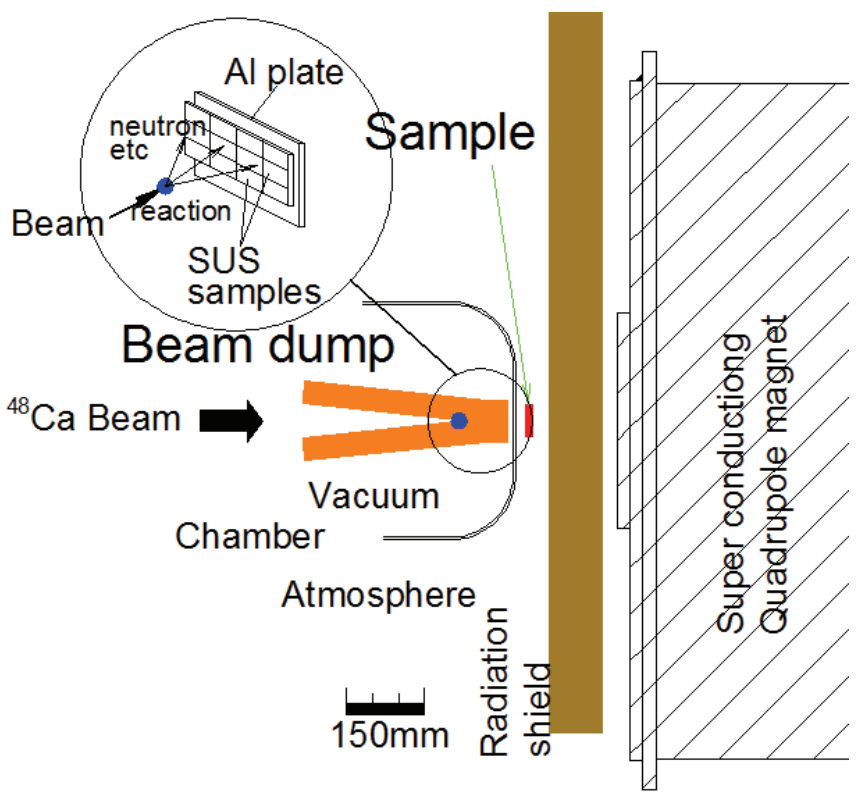

Fig. 1 Sectional side view of the experimental setup around the beam dump of the BigRIPS

As shown in Fig. 1, an array of SUS sample sheets were set on a $5 \mathrm{~mm}$-thick aluminum plate. The position of the beam spot was deduced from the residual activities of each SUS samples because it was difficult to measure the spot directly. Other samples are placed at the backside of the 
aluminum plate where the samples were expected to be just behind the beam spot on the beam dump. The size of beam spot was deduced from beam optics, measured beam emittance and observed size on the scintillation screen of F0 target position. This spot size on the beam dump was about $13 \mathrm{~mm}$ FWHM in horizontal direction and $5 \mathrm{~mm}$ in vertical direction. The total radiation dose was $6.5 \times 10^{14}$ (30 particle $\mathrm{nA}, \sim 1$ hour) of ${ }^{48} \mathrm{Ca}$ ions.

Table 1 Size of the sample set forward directions of the beam dump

\begin{tabular}{ll}
\hline Material & Size \\
\hline $\mathrm{Fe}$ & $10 \mathrm{~mm} \times 10 \mathrm{~mm} \times 1 \mathrm{~mm}$ \\
$\mathrm{Ni}$ & $10 \mathrm{~mm} \times 10 \mathrm{~mm} \times 1 \mathrm{~mm}$ \\
$\mathrm{Cr}$ & $10 \mathrm{~mm} \times 5 \mathrm{~mm}$ \\
$\mathrm{Cu}$ & $10 \mathrm{~mm} \times 10 \mathrm{~mm} \times 1 \mathrm{~mm}$ \\
$\mathrm{Al}$ & $10 \mathrm{~mm} \times 10 \mathrm{~mm} \times 1 \mathrm{~mm}$ \\
SUS304( Fe, Ni $8 \sim 10 \%, \mathrm{Cr}$ & $40 \mathrm{~mm} \times 40 \mathrm{~mm} \times 2 \mathrm{~mm}$ \\
$18 \sim 20 \%)$ & \\
\hline
\end{tabular}

\section{Radioactive Isotope Identification}

The residual gamma-ray spectra of the samples were measured by using a Ge detector Canberra GC2019. These spectra were measured several and 90 days after the irradiation to distinguish the short-lived and long-lived isotopes. Figure 2 shows a typical gamma-ray spectrum of the $\mathrm{Fe}$ sample.

Table 2 shows the identified radioactive isotopes of long-lived nuclides measured 90 days after the irradiation. Production rates of the residual nuclei were deduced from the peak area of the gamma-ray spectra, efficiency of the Ge detector and half-lives of observed nuclides. The peak effi-

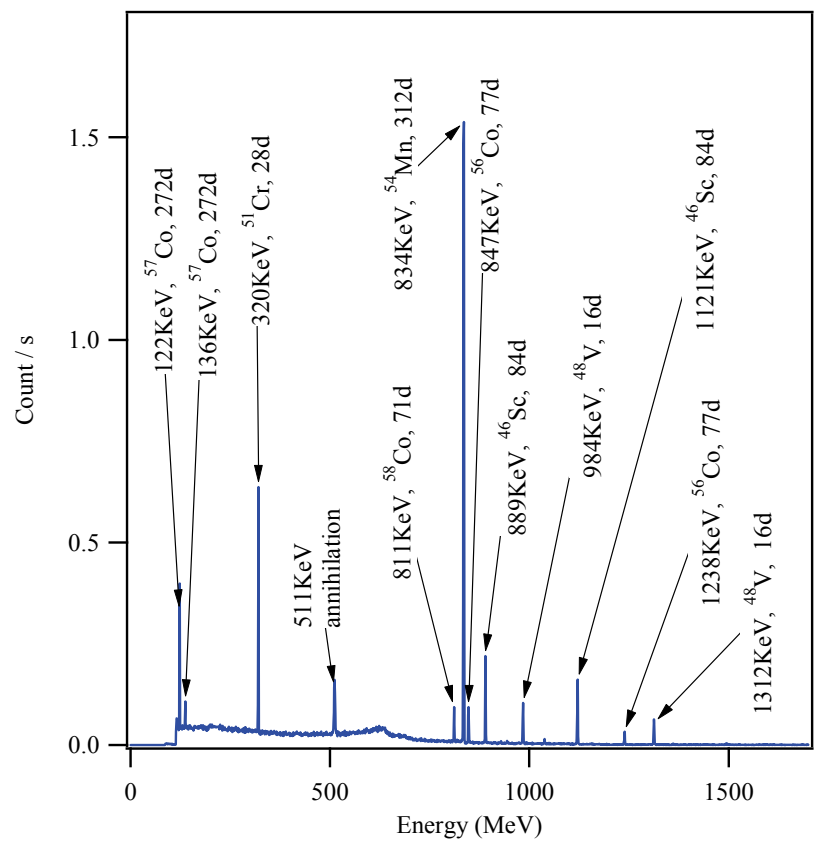

Fig. 2 Typical gamma-ray spectrum from the iron sample placed in the forward direction of the beam dump. This spectrum was measured 90 days after irradiated by the secondary particle from reaction of ${ }^{48} \mathrm{Ca} 345 \mathrm{MeV} /$ nucleon. Peak energies, identified nuclei, and their half lives are indicated. ciency of the Ge detector was determined using standard gamma-ray sources. The error of the production rate was taken account of the statistical error of the net-peak area, error of the gamma ray efficiency, and the accuracy of the sample positions.

In Table 2, only a part of nuclei observed in this study are listed. These nuclides were selected by the effective doses for practical use. From the gamma-ray energy and radiation intensity, effective doses of the gamma ray radiated from the samples were deduced using conversion coefficients of gamma-ray energy. ${ }^{4)}$ From the deduced dose from each nuclides and total value for each sample, dose ratio were obtained and listed in Table 2.

\section{Discussion}

The observed gamma-ray activities were compared with PHITS calculations. In PHITS, nucleus-nucleus collisions

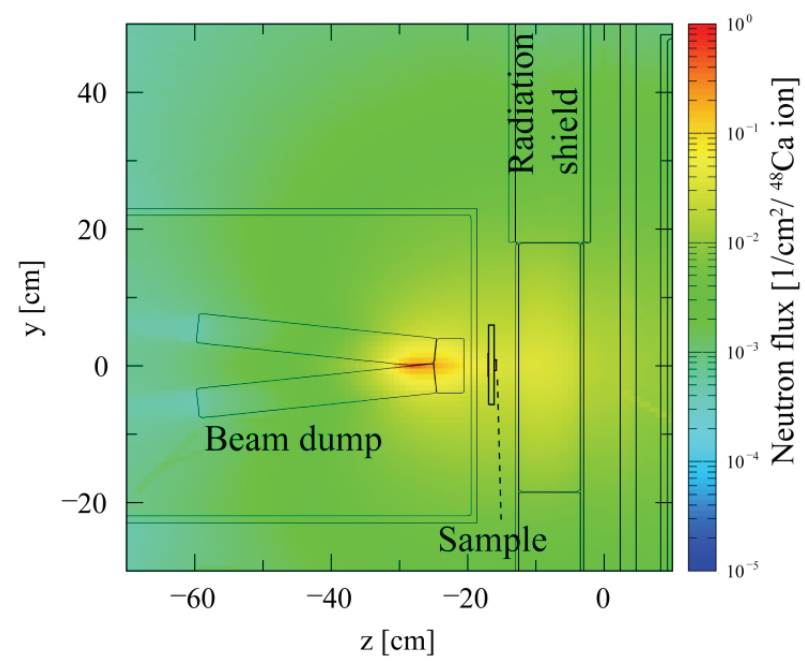

Fig. 3 Neutron flux intensity calculated with PHITS. It is shown on the sectional side view of the experimental setup around the beam dump.

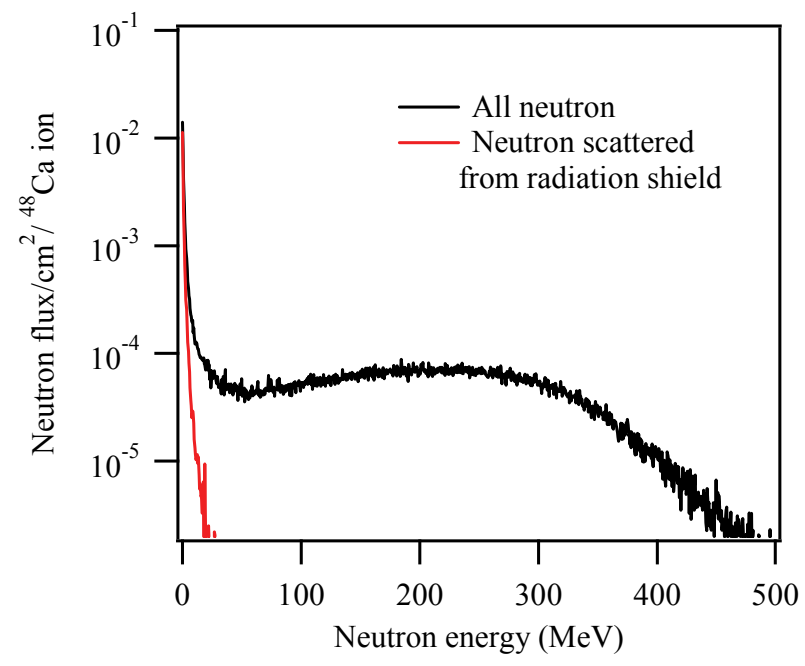

Fig. 4 Neutron spectra irradiated the Fe sample calculated with PHITS. Spectrum of backscattered neutron by the radiation shield near the samples is also shown. 
Table 2 Identified radioactivity of the samples measured at 90 days after ${ }^{48} \mathrm{C}$ beam irradiation. Though sample sizes are different each other as shown in Table 1, activity of all samples are normalized to $10 \mathrm{~mm} \times 10 \mathrm{~mm} \times 1 \mathrm{~mm}$ size sample. Energies and half lives of the nuclides are taken from the Table of Isotopes, eight editon. ${ }^{5)}$ Typical reaction and threshold energy in PHITS calculation are shown in this table.

\begin{tabular}{|c|c|c|c|c|c|c|c|}
\hline Sample & Nuclide & Half life & Energy (keV) & $\begin{array}{l}\text { Dose } \\
\text { ratio } \\
(\%) \\
\end{array}$ & $\begin{array}{l}\text { Production } \\
\text { rate }\left(1 / 10^{7}\right. \\
\left.{ }^{48} \mathrm{Ca} \text { ion }\right) \\
\end{array}$ & PHITS/EXP & $\begin{array}{c}\text { Reaction / } \\
\text { threshold }(\mathrm{MeV})\end{array}$ \\
\hline \multirow{4}{*}{$\begin{array}{c}\mathrm{Fe} \\
\left({ }^{54} \mathrm{Fe} 5.8 \%\right. \\
{ }^{56} \mathrm{Fe} 91.7 \% \\
{ }^{57} \mathrm{Fe} 2.2 \% \\
\left.{ }^{58} \mathrm{Fe} 0.3 \%\right)\end{array}$} & ${ }^{54} \mathrm{Mn}$ & $312.12 d$ & 835 & 56 & $111 \pm 18$ & $2.0 \pm 0.6$ & ${ }^{56} \mathrm{Fe}(\mathrm{n}, 2 \mathrm{n} \mathrm{p}){ }^{54} \mathrm{Mn} \quad / 20.4$ \\
\hline & ${ }^{46} \mathrm{Sc}$ & $83.79 \mathrm{~d}$ & 1121,889 & 18 & $7 \pm 1$ & $3.0 \pm 0.9$ & ${ }^{56} \mathrm{Fe}(\mathrm{n}, 4 \mathrm{n} 3 \mathrm{p} \alpha){ }^{46} \mathrm{Sc} / 67.4$ \\
\hline & ${ }^{48} \mathrm{~V}$ & $15.97 \mathrm{~d}$ & $\begin{array}{l}944,984 \\
1312,2240\end{array}$ & 10 & $17 \pm 3$ & $3.0 \pm 0.9$ & $\begin{array}{l}{ }^{56} \mathrm{Fe}(\mathrm{n}, 4 \mathrm{n} \mathrm{p} \alpha){ }^{48} \mathrm{~V} / 50.1 \\
{ }^{56} \mathrm{Fe}(\mathrm{n}, 5 \mathrm{n} 2 \mathrm{p} \mathrm{d}){ }^{48} \mathrm{~V} / 76.1\end{array}$ \\
\hline & ${ }^{56} \mathrm{Co}$ & $77.27 \mathrm{~d}$ & $\begin{array}{l}847,1038, \\
1238,1771 \text { etc }\end{array}$ & 7 & $2 \pm 1$ & $2.7 \pm 0.9$ & ${ }^{56} \mathrm{Fe}(\mathrm{p}, \mathrm{n}){ }^{56} \mathrm{Co} / 5.3$ \\
\hline \multirow{6}{*}{$\begin{array}{c}\mathrm{Ni} \\
\left({ }^{58} \mathrm{Ni} 67.8 \%\right. \\
{ }^{60} \mathrm{Ni} 26.2 \% \\
{ }^{61} \mathrm{Ni} 1.3 \% \\
{ }^{62} \mathrm{Ni} 3.7 \% \\
\left.{ }^{64} \mathrm{Ni} 1.2 \%\right)\end{array}$} & ${ }^{56} \mathrm{Co}$ & $77.27 \mathrm{~d}$ & $\begin{array}{l}847,1038, \\
1238,1771 \text { etc }\end{array}$ & 39 & $67 \pm 11$ & $2.4 \pm 0.7$ & ${ }^{58} \mathrm{Ni}(\mathrm{n}, 2 \mathrm{p} p)^{56} \mathrm{Co} / 19.5$ \\
\hline & ${ }^{58} \mathrm{Co}$ & $70.82 \mathrm{~d}$ & 811 & 33 & $151 \pm 25$ & $1.4 \pm 0.4^{*}$ & ${ }^{58} \mathrm{Ni}(\mathrm{n}, \mathrm{p}){ }^{58} \mathrm{Co} /-0.4$ \\
\hline & ${ }^{54} \mathrm{Mn}$ & $312.12 d$ & 835 & 4.3 & $42 \pm 7$ & $1.5 \pm 0.4$ & ${ }^{58} \mathrm{Ni}(\mathrm{n}, 2 \mathrm{n} 3 \mathrm{p})^{54} \mathrm{Mn} / 34.6$ \\
\hline & ${ }^{57} \mathrm{Co}$ & $271.79 d$ & $14,122,136$ & 3.3 & $186 \pm 31$ & $2.0 \pm 0.6^{* *}$ & ${ }^{58} \mathrm{Ni}(\mathrm{n}, \mathrm{n} \mathrm{p})^{57} \mathrm{Co} / 8.2$ \\
\hline & ${ }^{46} \mathrm{Sc}$ & $83.79 d$ & 1121,889 & 1.5 & $2.8 \pm 0.5$ & $1.5 \pm 0.5$ & $\begin{array}{l}{ }^{58} \mathrm{Ni}\left(\mathrm{n}, 4 \mathrm{n} 4 \mathrm{p} \mathrm{d}{ }^{3} \mathrm{He}\right)^{46} \mathrm{Sc} / 99.9 \\
{ }^{58} \mathrm{Ni}(\mathrm{n}, 2 \mathrm{n} 3 \mathrm{p} 2 \alpha){ }^{46} \mathrm{Sc} / 53.3 \\
{ }^{58} \mathrm{Ni}(\mathrm{n}, 4 \mathrm{n} 5 \mathrm{p} \alpha)^{46} \mathrm{Sc} / 81.6\end{array}$ \\
\hline & ${ }^{60} \mathrm{Co}$ & $5.27 \mathrm{y}$ & 1173,1333 & 0.6 & $11 \pm 2$ & $5.0 \pm 1.6^{\dagger}$ & ${ }^{60} \mathrm{Ni}(\mathrm{n}, \mathrm{p}){ }^{60} \mathrm{Co} / 2.0$ \\
\hline \multirow[t]{3}{*}{$\begin{array}{c}\mathrm{Cr} \\
{ }^{50} \mathrm{Cr} 4.3 \% \\
{ }^{52} \mathrm{Cr} 83.8 \% \\
{ }^{53} \mathrm{Cr} 9.6 \% \\
\left.{ }^{54} \mathrm{Cr} 2.4 \%\right)\end{array}$} & ${ }^{46} \mathrm{Sc}$ & $83.79 \mathrm{~d}$ & 1121,889 & 62 & $14 \pm 2$ & $2.1 \pm 0.6$ & $\begin{array}{l}{ }^{52} \mathrm{Cr}(\mathrm{n}, 4 \mathrm{n} 3 \mathrm{p}){ }^{46} \mathrm{Sc} / 59.7 \\
{ }^{52} \mathrm{Cr}(\mathrm{n}, 2 \mathrm{n} \mathrm{p} \mathrm{\alpha})^{46} \mathrm{Sc} / 31.4 \\
{ }^{52} \mathrm{Cr}(\mathrm{n}, 3 \mathrm{n} 2 \mathrm{pd}){ }^{46} \mathrm{Sc} / 57.5\end{array}$ \\
\hline & ${ }^{48} \mathrm{~V}$ & $15.97 \mathrm{~d}$ & $\begin{array}{l}944,984 \\
1312,2240\end{array}$ & 24 & $21 \pm 3$ & $2.9 \pm 0.9$ & $\begin{array}{l}{ }^{52} \mathrm{Cr}(\mathrm{n}, 4 \mathrm{n} p)^{48} \mathrm{~V} / 42.4 \\
{ }^{50} \mathrm{Cr}(\mathrm{n}, 2 \mathrm{n} p)^{48} \mathrm{~V} / 21.1\end{array}$ \\
\hline & ${ }^{51} \mathrm{Cr}$ & $27.7 d$ & 320 & 4.8 & $88 \pm 15$ & $2.0 \pm 0.6^{* *}$ & $\begin{array}{l}{ }^{52} \mathrm{Cr}(\mathrm{n}, 2 \mathrm{n}){ }^{51} \mathrm{Cr} / 12.0 \\
{ }^{50} \mathrm{Cr}(\mathrm{p},-)^{51} \mathrm{Cr} /-8.5\end{array}$ \\
\hline
\end{tabular}

*: In PHITS calculation, $14 \%$ of ${ }^{58}$ Co are generated by backscattered neutrons from the radiation shield.

**: In PHITS calculation, $2 \%$ of nuclei are generated by backscattered neutrons from the radiation shield.

${ }^{\dagger}$ : In PHITS calculation, $12 \%$ of ${ }^{60} \mathrm{Co}$ are generated by backscattered neutrons from the radiation shield.

are described by the JAERI Quantum Molecular Dynamics (JQMD) model, ${ }^{6}$ ) and the Generalized Evaporation Model $(\mathrm{GEM})^{7)}$ is used for evaporation and fission process of the excited states. To calculate neutron-induced reactions below $20 \mathrm{MeV}$, the ENDF/B-VII library was applied.

Production rates of radioisotope nuclei in the samples were obtained with PHITS. A million event source of ${ }^{48} \mathrm{Ca}$ ion was produced in the calculation. Particles irradiated the samples were mainly neutron because most of charged particles were absorbed in the beam dump. Figure 3 shows the calculated distribution of the flux intensity of neutrons. Neutrons from the beam dump bombarded on the sample. Part of incident neutrons were possible to come from the radiation shield. Figure 4 shows a neutron spectrum bombarded the Fe sample calculated by PHITS. To estimate the effect of incident neutrons scattered by the thick-radiation shield located near the sample, the neutron spectrum from the shield is also shown in Fig. 4. Energy of the scattered neutron is less than $20 \mathrm{MeV}$.

Using PHITS, production rate of radioactive isotopes 
Table 2 (Continued)

\begin{tabular}{|c|c|c|c|c|c|c|c|}
\hline Sample & Nuclide & Half life & Energy (keV) & $\begin{array}{l}\text { Dose } \\
\text { ratio } \\
(\%) \\
\end{array}$ & $\begin{array}{l}\text { Production } \\
\text { rate }\left(1 / 10^{7}\right. \\
\left.{ }^{48} \mathrm{Ca} \text { ion }\right) \\
\end{array}$ & PHITS/EXP & $\begin{array}{c}\text { Reaction / } \\
\text { threshold (MeV) }\end{array}$ \\
\hline \multirow[t]{6}{*}{$\begin{array}{c}\mathrm{Cu} \\
\left({ }^{63} \mathrm{Cu}\right. \\
69.1 \% \\
{ }^{65} \mathrm{Cu} \\
30.9 \%)\end{array}$} & ${ }^{58} \mathrm{Co}$ & $70.82 \mathrm{~d}$ & 811 & 43 & $108 \pm 18$ & $1.9 \pm 0.6$ & $\begin{array}{l}{ }^{63} \mathrm{Cu}(\mathrm{n}, 4 \mathrm{n} 2 \mathrm{p}){ }^{58} \mathrm{Co} / 44.5 \\
{ }^{63} \mathrm{Cu}(\mathrm{n}, 2 \mathrm{n} \alpha){ }^{58} \mathrm{Co} / 16.2 \\
{ }^{65} \mathrm{Cu}(\mathrm{n}, 6 \mathrm{n} 2 \mathrm{p}){ }^{58} \mathrm{Co} / 62.4 \\
{ }^{65} \mathrm{Cu}(\mathrm{n}, 4 \mathrm{n} \alpha){ }^{58} \mathrm{Co} / 34.1\end{array}$ \\
\hline & ${ }^{56} \mathrm{Co}$ & $77.27 \mathrm{~d}$ & $\begin{array}{l}847,1038, \\
1238,1771 \text { etc }\end{array}$ & 21 & $16 \pm 3$ & $2.1 \pm 0.6$ & $\begin{array}{l}{ }^{63} \mathrm{Cu}(\mathrm{n}, 6 \mathrm{n} 2 \mathrm{p}){ }^{56} \mathrm{Co} / 64.5 \\
{ }^{63} \mathrm{Cu}(\mathrm{n}, 4 \mathrm{n} \alpha){ }^{56} \mathrm{Co} / 36.2\end{array}$ \\
\hline & Ann. & & 511 & 8.9 & & & \\
\hline & ${ }^{54} \mathrm{Mn}$ & $312.12 \mathrm{~d}$ & 835 & 8.7 & $48 \pm 8$ & $2.0 \pm 0.6$ & $\begin{array}{l}{ }^{63} \mathrm{Cu}(\mathrm{n}, 4 \mathrm{n} 2 \mathrm{p} \alpha){ }^{54} \mathrm{Mn} / 51.2 \\
{ }^{63} \mathrm{Cu}(\mathrm{n}, 6 \mathrm{n} 4 \mathrm{p}){ }^{54} \mathrm{Mn} / 79.5\end{array}$ \\
\hline & ${ }^{60} \mathrm{Co}$ & $5.27 \mathrm{y}$ & 1173,1333 & 4.6 & $46 \pm 8$ & $2.8 \pm 0.9$ & $\begin{array}{l}{ }^{63} \mathrm{Cu}(\mathrm{n}, 2 \mathrm{n} 2 \mathrm{p}){ }^{60} \mathrm{Co} / 26.6 \\
{ }^{65} \mathrm{Cu}(\mathrm{n}, 4 \mathrm{n} 2 \mathrm{p}){ }^{60} \mathrm{Co} / 44.4\end{array}$ \\
\hline & ${ }^{59} \mathrm{Fe}$ & $44.5 \mathrm{~d}$ & $\begin{array}{l}143,192 \\
1099,1292\end{array}$ & 4 & $8 \pm 1$ & $2.5 \pm 0.8$ & $\begin{array}{l}{ }^{63} \mathrm{Cu}(\mathrm{n}, 2 \mathrm{n} \mathrm{3p}){ }^{59} \mathrm{Fe} / 34.9 \\
{ }^{65} \mathrm{Cu}(\mathrm{n}, 4 \mathrm{n} 3 \mathrm{p}){ }^{59} \mathrm{Fe} / 52.7\end{array}$ \\
\hline \multirow{3}{*}{$\begin{array}{c}\mathrm{Al} \\
\left({ }^{27} \mathrm{Al}\right. \\
100 \%)\end{array}$} & Ann. & & 511 & 56 & & & \multirow{3}{*}{$\begin{array}{l}{ }^{27} \mathrm{Al}(\mathrm{n}, 4 \mathrm{n} 2 \mathrm{p})^{22} \mathrm{Na} / 50.8 \\
{ }^{27} \mathrm{Al}\left(\mathrm{n}, 3 \mathrm{n} 2 \alpha^{10} \mathrm{~B}\right)^{7} \mathrm{Be} / 66.0 \\
\text { various reaction channels }\end{array}$} \\
\hline & ${ }^{22} \mathrm{Na}$ & $2.6 y$ & 1275 & 38 & $11 \pm 2$ & $2.8 \pm 0.9$ & \\
\hline & ${ }^{7} \mathrm{Be}$ & $53.29 d$ & 478 & 1.3 & $0.9 \pm 0.2$ & $1.0 \pm 0.4$ & \\
\hline \multirow{7}{*}{\begin{tabular}{l}
\multicolumn{1}{c}{ SUS } \\
$(\mathrm{Fe}$ \\
$70 \sim 74 \%$ \\
$\mathrm{Ni} 8 \sim 10 \%$ \\
$\mathrm{Cr}$ \\
$18 \sim 20 \%)$
\end{tabular}} & ${ }^{54} \mathrm{Mn}$ & $312.12 d$ & 835 & 31 & $107 \pm 18$ & $2.2 \pm 0.4$ & \\
\hline & ${ }^{46} \mathrm{Sc}$ & $83.79 d$ & 1121,889 & 22 & $15 \pm 3$ & $2.2 \pm 0.4$ & \\
\hline & ${ }^{56} \mathrm{Co}$ & $77.27 \mathrm{~d}$ & $\begin{array}{l}847,1038, \\
1238,1771 \text { etc }\end{array}$ & 20 & $9 \pm 2$ & $3.3 \pm 0.6$ & \\
\hline & ${ }^{48} \mathrm{~V}$ & $15.97 \mathrm{~d}$ & $\begin{array}{l}944,984, \\
1312,2240\end{array}$ & 10 & $27 \pm 5$ & $2.3 \pm 0.4$ & \\
\hline & ${ }^{58} \mathrm{Co}$ & $70.82 d$ & 811 & 7.6 & $12 \pm 2$ & $1.8 \pm 0.3$ & \\
\hline & ${ }^{57} \mathrm{Co}$ & $271.79 d$ & $14,122,136$ & 0.8 & $32 \pm 5$ & $2.8 \pm 0.5$ & \\
\hline & ${ }^{60} \mathrm{Co}$ & $5.27 \mathrm{y}$ & 1173,1333 & 0.2 & $2.3 \pm 0.4$ & $5.0 \pm 1.0$ & \\
\hline
\end{tabular}

were obtained. The production rate of the samples were compared with the PHITS results, as listed in Table 2. Threshold energy are also shown. In the cases that the threshold energy is less than $20 \mathrm{MeV}$, neutron-induced reaction rates in the samples with the scattered neutron by the shield were also calculated. As a result, $14 \%$ of ${ }^{58} \mathrm{Co}$ and $12 \%{ }^{60} \mathrm{Co}$ are produced by the scattered neutron in the $\mathrm{Ni}$ sample. In other cases, the effects of the scattered neutron were enough small.

In this study, production rates with PHITS calculation are higher than experimental them. The difference is possible to originate from the production of high energy neutron from the ${ }^{48} \mathrm{Ca}$ nucleus. T. Ohnishi et al. measured radiation heat load to the superconducting magnet around a beryllium-production target with ${ }^{48} \mathrm{Ca}$ beam. ${ }^{8)}$ The PHITS result was 1.5 times higher than measured heat load.

Angular distributions of secondary neutrons from thick-several targets with heavy ion beams were measured by Satoh et al. and compared with the PHITS calculation. ${ }^{9)}$ The beam nuclides were from $\mathrm{He}$ to $\mathrm{Xe}$ and energy was 400 800 MeV/nucleon. In their work, a Fe ion bombardment on $\mathrm{Cu}$ target is the similar case of the ${ }^{48} \mathrm{Ca}$ on copper dump. In the high energy region of the neutron spectrum emitted to the forward direction of $\mathrm{Cu}$ target, the PHITS result, in their study, was higher than the experimental result. Therefore, result of this study shows the same tendency of other studies of reaction near a ${ }^{48} \mathrm{Ca}$ nuclide. In some other beam and target cases, neutron spectra of PHITS result were smaller than that of experiment. Further study is expected.

\section{Conclusion}

Residual activities of the radiation samples were measured. $\mathrm{A}^{48} \mathrm{Ca}$ at $345 \mathrm{MeV} /$ nucleon beam was injected to the 
beam dump of the BigRIPS. Secondary neutron from the beam dump irradiated and activated the samples which were located in the forward direction. Via gamma-ray measurements at several and 90 days after, short- and long-lived radioactive isotopes were identified. Observed radioactivity was compared with the PHITS calculation. The PHITS results were higher than the experiment. These results are useful to estimate the future level of residual-radiation of the BigRIPS.

\section{Acknowledgment}

The PHITS calculation was performed by using the RIKEN Integrated Cluster of Clusters (RICC) facility, which allows fast and large-size computation. We thank for supporting the computing facilities essential for the completion of the work.

\section{References}

1) Y. Yano, "The RIKEN RI Beam Factory Project: A status report," Nucl. Instr. Meth. Phys. Res., B261, 1009-1013 (2007).

2) T. Kubo, "In-flight RI beam separator BigRIPS at RIKEN and elsewhere in Japan," Nucl. Instr. Meth. Phys. Res., B204, 97-113 (2003).

3) K. Niita et al., PHITS: Particle and Heavy Ion Transport code System, Version 2.23, JAEA-Data/Code 2010-022, Japan Atmic Energy Agency (JAEA) (2010).

4) ICRP, ICRP Publication 74: Conversion Coefficients for use in Radiological Protection against External Radiation, 74, Annals of the ICRP 26, No.3/4, Elsevier, Amsterdam (1996).

5) R. B. Firstone et al., Table of Isotopes Eighth Edition, John Wiley \& Sons, New York (1996).

6) K. Niita et al., "Analysis of the ( $\left.\mathrm{N}, \mathrm{xN}^{\prime}\right)$ reactions by quantum molecular dynamixs plus statistical decay model," Phys. Rev., C52, 2620 (1995).

7) S. Furihata, "Statistical analysis of light fragment production from medium energy proton-induced reactions," Nucl. Instr. Meth. Phys. Res., B171, 251-258 (2000).

8) T. Ohnish et al., "Radiation transport calculation using PHITS code for Radiation heat load and damage to superconducting radioactive isotope beam separator BigRIPS at RIKEN," in this volume.

9) D. Satoh et al., "Reevaluation of secondary neutron spectra from thick target upon heavy-ion bombardment," Nucl. Instr. Meth. Phys. Res., B204, 97-113 (2003). 